\title{
The Fellowship Competitiveness Index: A Novel Way to Estimate Admission Competition into Internal Medicine Subspecialties
}

Huynh Wynn Tran ( $D$ Huynh.tran@wynnmedcenter.com )

California Northstate University College of Medicine https://orcid.org/0000-0002-0661-2345

Russell W. De Jong

California Northstate University College of Medicine

Quinto Gesiotto

California Northstate University College of Medicine

\section{Research article}

Keywords: Competitiveness, Internal Medicine, Fellowship, Cardiology, Hematology/Oncology,

Nephrology, Subspecialty

Posted Date: August 28th, 2019

DOI: https://doi.org/10.21203/rs.2.10863/v1

License: (c) (i) This work is licensed under a Creative Commons Attribution 4.0 International License.

Read Full License 


\section{Abstract}

Background The competitiveness of internal medicine (IM) fellowships have not been well studied. Our novel competitiveness metric aims to estimate IM subspecialty fellowships entry competitiveness in a single, concise number that is easily accessible and understandable. Through this we hope to offer assistance to prospective fellowship applicants in making an educated and realistic fellowship choice. Methods Fellowship filled percentages, the percentage of applications from US medical graduates (USMGs), average matriculating USMLE Step 1 scores, and average post-fellowship salary were used to construct our metric. Procedural specialties included cardiology, pulmonary/critical care, and gastroenterology. Non-procedural specialties included hematology/oncology, rheumatology, endocrinology, infectious disease, and nephrology. Data were gathered from the National Resident Matching Program (NRMP) 2009 - 2018 reports, Medscape's Physician Compensation Reports, and other sources used to corroborate salaries. Results 2018 procedural $\mathrm{FCl}$ (25.92) was higher than nonprocedural (15.61). Cardiology ( $\mathrm{FCl} 28.72$, salary $\$ 423,000$, Step 1237.67$)$ was the most competitive field. Hematology/oncology leads non-procedural fields in FCI (28.02), USMG percentage (60\%), and salary $(\$ 363,000)$. Nephrology fill rates have declined from $94.8 \%$ to $60.1 \%$ despite $32 \%$ salary increase, giving it the lowest $\mathrm{FCl}$ (7.04). Conclusions Calculations show procedural specialties are most competitive, with cardiology at the top. Hematology/oncology leads non-procedural fields and is approaching procedural competitiveness, as evidenced by multiple factors that rival or surpass gastroenterology and pulmonary/critical care. We believe that this metric is a simple, accessible, and valid measure of competitiveness of fellowship entry and with further manipulation can be generalized to residency competitiveness.

\section{Background}

For many years, there has been a spectrum of admission competitiveness into internal medicine subspecialty fellowships. Procedural subspecialties usually lead in terms of competitiveness while the nonprocedural subspecialties are behind. Possible reasons for this trend include better compensation, job availability, and higher professional satisfaction in the procedural fields. In recent years, some nonprocedural programs have had difficulty filling their available training slots 1 .

Recently, fellowship application trends have changed as applicants began to value more work-life balance 2 and as diagnostics and therapeutics among nonprocedural fields have advanced. This study's objective is to analyze data trends from 2009 to 2018 to predict future subspecialty competitiveness through the creation of a novel standardized metric called the Fellowship Competitiveness Index ( $\mathrm{FCl})$.

\section{Methods}


We examined annual percentage of offered fellowship positions filled, percentage of total fellowship positions filled by United States medical school graduates (USMGs), average matriculating United States Medical Licensing Exam (USMLE) Step 1 scores, and post fellowship salary trends from 2009 to 2018. Data were obtained from the National Resident Matching Program (NRMP) and the annual MedScape Physician Compensation Report. Salary data was corroborated by multiple sources 3, 4, 5, 6 .

We used this data to calculate the $\mathrm{FCl}$ for procedural and non-procedural internal medicine subspecialties. Cardiology, pulmonary/critical care, and gastroenterology were included in the procedural group, while rheumatology, endocrinology, hematology/oncology, infectious disease, and nephrology were included in the non-procedural group. All internal medicine subspecialty programs that reported to the NRMP were included. We recognized this study did not cover the breadth of internal medicine (IM) subspecialization. Geriatrics, allergy and immunology, sports medicine, and palliative care were excluded due to relative small size and/or multiple pathways to fellowship.

Descriptive statistics were calculated to provide the $\mathrm{FCl}$ validity through comparison. For each parameter, we calculated percentage change from the baseline year through the present day as mean \pm standard error of the mean (SEM). The full mean \pm SEM calculation was omitted where change was not significant or where data was insufficient. The baseline year was 2009 for percent fill and percentage of positions filled by USMGs, and 2011 for salary data and average Step 1 scores. Data for Step 1 scores was only reported by the NRMP in 2011 and 2018. All statistical analyses were conducted using GraphPad Online QuickCalcs (GraphPad Software, La Jolla, CA 92037). The study utilized de-identified publicly available data.

To calculate Fellowship Competitive Index, each factor was converted to a numerical scale. Percentage of fellowship positions filled was converted to a 10 scale where each subspecialty fill percentage was divided by 10 . For example, a $72.3 \%$ fill was converted to a score of 7.23. Percentage of positions filled by USMGs was converted by the same method. Salary factor was calculated by the equation [(average subspecialist salary- average internist salary)/ average internist salary] $\mathrm{x} 10$. This formula allowed negative results, which took into account the negative impact a lower salary had on a subspecialty's competitiveness. For example, the average gastroenterology and internal medicine salaries in 2018 were $\$ 408,000$ and $\$ 230,000$, respectively. When plugged into the equation, the gastroenterology salary factor was $[(\$ 408,000$ - $\$ 230,000) / \$ 230,000]$ x $10=7.74$. USMLE Step 1 factor was calculated by subtracting the average internal medicine matriculants' Step 1 score of that year from the specialty's average matriculant score. For example, cardiology's 2018 average score was 237.6 and internal medicine's was 233 7. Therefore, the score was $237.67-233=4.67$. This calculation allows for negative results for the same reason the salary formula did. Finally, all factors were added to give the final FCl. 


\section{Results}

For procedural subspecialties, the percentage fill has increased from $97.1 \%$ to $99.1 \%$ (Figure 1). There has been a decline in percentage of positions filled by USMGs from $57.8 \%$ to $56.5 \%$. Step 1 scores increased 11.67 points from 225 to 236.67 . Average salaries have increased $\$ 101,000(26.3 \%)$, from $\$ 283,000$ to $\$ 384,000$. The average annual increase is $\$ 14,300 \pm \$ 4,000(+4.6 \% \pm 1.3)$.

For non-procedural subspecialties, the percent of filled fellowship positions have fallen from $91.8 \%$ to $83.4 \%(-1.1 \% \pm 1.2$ per year) (Figure 1). The percent of positions filled by USMGs has fallen from 45.5 to $39.8(-1.6 \% \pm 1.7$ per year). Step 1 scores have increased 14 points from 220.33 to 234.33 . Average salaries have increased from $\$ 212,000$ to $\$ 275,000$, with an average annual increase of $\$ 10,400 \pm \$ 3,300$ $(+4.2 \% \pm 1.4)$.

Cardiology fill percentage has held steady at 99.1\% (Figure 2). USMG position fill percentage has also fallen from $60.7 \%$ to $56.5 \%$, with an average annual decline of $-1 \% \pm 1.3$ (Figure 3 ). USMLE scores have improved 10.67 points from 227 to 237.67 . Average salaries have seen an increase from $\$ 320,000$ to $\$ 423,000$ which is the leading average salary in any of the subspecialties included in this study. The average annual increase was $\$ 14,700 \pm \$ 7,500(+3.8 \% \pm 2)$.

Pulmonary/critical care fill percentage has increased marginally from $96 \%$ to $99.5 \%$. The percentage of positions filled by USMGs has increased slightly from $48.7 \%$ to $50.7 \%$, both the lowest percentage within the procedural specialties. Step 1 scores have increased 13 points from 223.33 to 236.33 . Finally, mean salaries have increased $28.3 \%$ from $\$ 230,000$ to $\$ 321,000$, an average annual increase of $\$ 13,000 \pm$ $\$ 3,000(+4.6 \% \pm 1.1)$.

Gastroenterology fill percentage has remained high, increasing from $96.3 \%$ to $98.6 \%$. USMG position fill percentage has decreased from $70.8 \%$ to $61.3 \%$, still the highest percentage of any specialty included in this study. Step 1 scores have increased 11.66 points from 224.67 to 236.33 . Salaries have increased $26.5 \%$ from $\$ 300,000$ to $\$ 408,000$, an average annual increase of $\$ 15,400 \pm \$ 4,600(+4.2 \% \pm 1.3)$.

Rheumatology grew in fill percentage from $92.1 \%$ to $98.6 \%$. Percentage of positions filled by USMGs decreased from $50.9 \%$ in 2009 to $32 \%$ in 2014 , an average annual decline of $-8.2 \% \pm 2.3$, but strongly rebounded with an average annual increase of $11.9 \pm 3$ to $53.4 \%$ in 2018. Step 1 scores have increased 
14.67 points from 220 to 234.67 . Salaries have increased by $29.9 \%$ from $\$ 180,000$ to $\$ 257,000$, an average annual increase of $\$ 11,000 \pm \$ 5,700(+4.8 \% \pm 2.5)$.

Endocrinology fill percentage has increased from $87.4 \%$ to $92.9 \%$. Percentage of positions filled by USMGs has declined from $44.4 \%$ to $39.7 \%$, an average decline of $-1.4 \% \pm 2.1$. Endocrinology USMG fill percentage trends have followed those of rheumatology, dropping sharply from 2009 - 2014 then rising. Step 1 scores have increased from 14.33 points from 221 to 235.33. Average salaries have increased $19.8 \%$ from $\$ 170,000$ to $\$ 212,000$, which lags behind all other specialties examined both in dollar amount and rate of increase. The average annual increase was $+\$ 6,000 \pm \$ 3,000(+3 \% \pm 1.5)$.

Hematology/oncology fill rates have increased slightly from $98.1 \%$ to $99.1 \%$ (Figure 2). This field's selectivity has grown as evidenced by a percent fill by USMG increase from $51.2 \%$ to $60 \%$ (Figure 3 ). The average annual increase was $+1.6 \% \pm 1.7$. This includes a $+7.2 \%$ spike observed in the 2018 applicant pool. Step 1 scores have increased 15 points, the largest increase seen here, from 224.33 to 239.33. Average salaries have historically been the highest of the non-procedural specialties, and the trend continues here. They have increased $20.1 \%$ from $\$ 290,000$ to $\$ 363,000$, an average annual increase of $+\$ 10,400 \pm \$ 6,300(+3 \% \pm 1.9)$.

Infectious disease fill rate has fallen from $90.5 \%$ to $81.5 \%$, an average annual decline of $-1.4 \pm 2.6$. Fill rates went as low as $65.1 \%$ in 2016 but have rebounded to $81.5 \%$. Percentage of positions filled by USMGs has fallen from $48.8 \%$ to $40.1 \%$. The average annual decline is $-3.4 \% \pm 3.5$. Step 1 scores have increased 14 points from 218.33 to 232.33 . Average annual salaries have increased $25.1 \%$ from $\$ 173,000$ to $\$ 231,000$. The average annual increase was $+\$ 8,300 \pm \$ 5,500(+3.8 \% \pm 2.6)$.

Nephrology displayed some interesting trends. Fill rates have plummeted from $94.8 \%$ to $60.1 \%$, an average annual decline of $-5.4 \% \pm 2.4$ (Figure 3 ). Percent of positions filled by USMGs has followed the trend, declining $46.7 \%$ from $36 \%$ to $19.2 \%$, an average annual decline is $-8.4 \pm 5.4$ (Figure 3 ). Step 1 scores have increased 10 points, the smallest increase observed, from 219.33 to 229.33 . Average salaries have increased $32 \%$ from $\$ 200,000$ to $\$ 294,000$, the largest increase, percentage wise, seen in this study. The average annual increase is $+\$ 14,700 \pm \$ 4,700(+5.3 \% \pm 1.6)$.

\section{Discussion}

Our data suggested that procedural specialties will continue to lead in terms of competitiveness based on $\mathrm{FCl}$ (Table 1). Cardiology has the highest $\mathrm{FCl}$ and will be the most competitive subspecialty to match into 
in the near future. In 2018 , it claimed the highest salary $(\$ 423,000)$ and average Step 1 score $(237.66)$, as well as the second highest percentage of positions filled by USMGs (57.5\%).

Hematology/Oncology has the second highest 2018 FCl. Their 2018 fill percentage by USMGs (60\%, Figure 4), and average salary $(\$ 363,000)$ both rival or surpass those of gastroenterology and pulmonary/critical care, but still lag behind cardiology.

Nephrology has the lowest $2018 \mathrm{FCl}$. In 2009, it was one of the hardest specialties to match into, with a $94.8 \%$ fill rate. In 2018 , the specialty filled $60.1 \%$ of their available positions. We are unsure what to attribute this to as the average salary in the field has increased $32 \%$ since 2011 which lead to the second highest salary within the non-procedural group. Some possible causes include a greater focus on work life balance, the rise of outpatient dialysis centers, and increasing internist salaries.

Our study has several possible limitations. This is an observational study. The data may be of limited quality. The response rate of participants surveyed for salary on Medscape data for was low (4\%) which may not represent actual compensation. We tried to mitigate this with our other salary sources. While the NRMP Match data adequately evaluates the actual rate of change in fellowship competitiveness, the forces driving this are less clear and merit further study. Lastly, percent of positions filled by USMGs is not a proven surrogate for the selectivity of a subspecialty, although it is often used this way.

Strengths of our study are that the NRMP and Medscape data are clear and respected, the study is simple and straightforward, and the raw numbers and trends are apparent and support the conclusions we drew from our new metric.

\section{Conclusions}

$\mathrm{FCl}$ was created as a standardized method to calculate subspecialty competitiveness. This index may not account for all competitiveness, as there are other metrics which are not included in the calculation. We constructed the metric to place less weight on Step 1 to represent our assertion that, while still salient to the fellowship match, Step 1 scores do not carry the same supreme importance as they do in the residency match 8 . It may have shortcomings as a year to year evaluator of competition since the NRMP does not release Step 1 score data for fellowship applicants every year. We believe that with additional 
adjustments, this metric could be expanded to represent other residency competitiveness in a similar manner to what we have achieved with IM subspecialties.

\section{Abbreviations}

FCl- Fellowship Competitiveness Index, USMG- United States Medical Graduate, USMLE- United States Medical Licensing Exam, NRMP- National Resident Matching Program, IM- Internal Medicine, SEMstandard error of the mean

\section{Declarations}

Ethics approval and consent to participate: Not applicable

Consent for publication: Not applicable

Availability of data and materials: The datasets analysed during the current study are publicly available from sources listed in the References section

Competing interests: The authors declare that they have no competing interests

Funding: There is no funding to report

Authors' contributions: RDJ analyzed the data, elucidated the results, wrote the first draft of the manuscript, assisted with development of the Fellowship Competitiveness Index metric, assisted with editing, and created the first draft of all figures, QJ wrote the first draft of the abstract, assisted with development of the Fellowship Competitiveness Index, and assisted with editing, HT initiated the project, suggested the creation of the Fellowship Competitiveness Index, and was the principle editor. All authors read and approve the final manuscript.

Acknowledgements: Not applicable

\section{References}


1. Liang M. Charting Outcomes in the Match [Internet]. National Residency Matching Program; 2018 [cited 2018Dec]. Available from: https://mkOnrmpcikgb8jxyd19h.kinstacdn.com/wpcontent/uploads/2018/10/2018-Charting-Outcomes-SMS.pdf.

2. Martin KL. Medscape Physician Lifestyle \& Happiness Report 2019 [Internet]. Medscape; 2019 [cited 2019Jan17]. Available from: https://www.medscape.com/slideshow/2019-lifestyle-happiness6011057

3. Kane L. Medscape Physician Lifestyle \& Happiness Report 2018 [Internet]. Medscape; 2018 [cited 2018Dec]. Available from: https://www.medscape.com/slideshow/2018-compensation-overview6009667

4. 2018 Compilation of Physician Compensation Surveys [Internet]. Merritt Hawkins; Available from: https://www.merritthawkins.com/uploadedFiles/merritthawkins_2018_compensation_brochure.pdf

5. 2018 Physician Compensation Report [Internet]. Doximity; Available from: https://s3.amazonaws.com/s3.doximity.com/careers/2018_physician_compensation_report.pdf

6. Quigley L, Salsberg E, Collins A. Survey of 2018 Nephrology Fellows [Internet]. The American Society of Nephrology; 2018. Available from: https://www.asnonline.org/education/training/workforce/Nephrology_Fellow_Survey_Report_2018_Highlights.pdf

7. National Resident Matching Program, Charting Outcomes in the Match: U.S. Allopathic Seniors, 2018. National Resident Matching Program, Washington, DC 2018.

8. National Resident Matching Program, Data Release and Research Committee: Results of the 2018 NRMP Program Director Survey. National Resident Matching Program, Washington, DC. 2018.

\section{Tables}

Table 1: Fellowship Competitiveness Index table for all specialties, sorted from highest to lowest 2018 FCI. 2011 FCI provided for comparison. 


\begin{tabular}{|c|c|c|c|c|c|c|}
\hline & $\begin{array}{l}2018 \text { percent of } \\
\text { positions filled }\end{array}$ & $\begin{array}{l}2018 \text { percent of } \\
\text { positions filled by } \\
\text { USMGs }\end{array}$ & $\begin{array}{l}2018 \\
\text { salary }\end{array}$ & $\begin{array}{l}2018 \text { USMLE Step } 1 \\
\text { average matriculant } \\
\text { score }\end{array}$ & $\begin{array}{l}2018 \\
\text { FCI }\end{array}$ & $\begin{array}{l}2011 \\
\text { FCI }\end{array}$ \\
\hline Cardiology & 9.91 & 5.75 & 8.39 & 4.67 & 28.72 & 28.02 \\
\hline $\begin{array}{l}\text { Hematology/ } \\
\text { Oncology }\end{array}$ & 9.91 & 6.00 & 5.78 & 6.33 & 28.02 & 22.69 \\
\hline Gastroenterology & 9.86 & 6.13 & 7.74 & 3.33 & 27.06 & 24.67 \\
\hline $\begin{array}{l}\text { Procedural } \\
\text { Specialties }\end{array}$ & 9.91 & 5.65 & 6.69 & 3.67 & 25.92 & 23.21 \\
\hline $\begin{array}{l}\text { Pulmonary/ } \\
\text { Critical Care }\end{array}$ & 9.95 & 5.07 & 3.96 & 3.33 & 22.31 & 16.91 \\
\hline Rheumatology & 9.86 & 5.34 & 1.17 & 1.67 & 18.04 & 9.21 \\
\hline $\begin{array}{l}\text { Non-Procedural } \\
\text { Specialties }\end{array}$ & 8.34 & 3.98 & 1.96 & 1.33 & 15.61 & 11.39 \\
\hline Endocrinology & 9.29 & 3.97 & -.78 & 2.33 & 14.81 & 10.07 \\
\hline $\begin{array}{l}\text { Infectious } \\
\text { Disease }\end{array}$ & 8.15 & 4.01 & .04 & -.67 & 11.53 & 6.31 \\
\hline Nephrology & 6.01 & 1.92 & 2.78 & -3.67 & 7.04 & 8.16 \\
\hline
\end{tabular}

Figures 
100

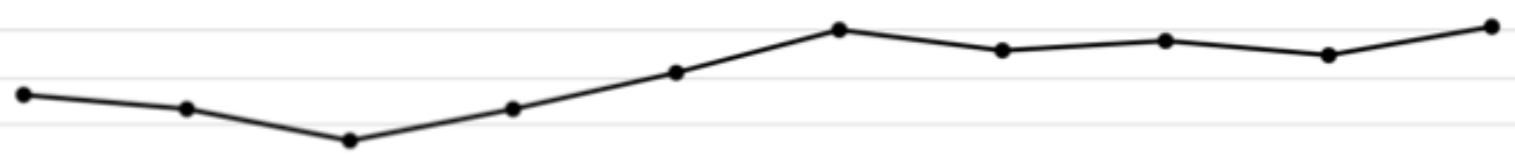

95
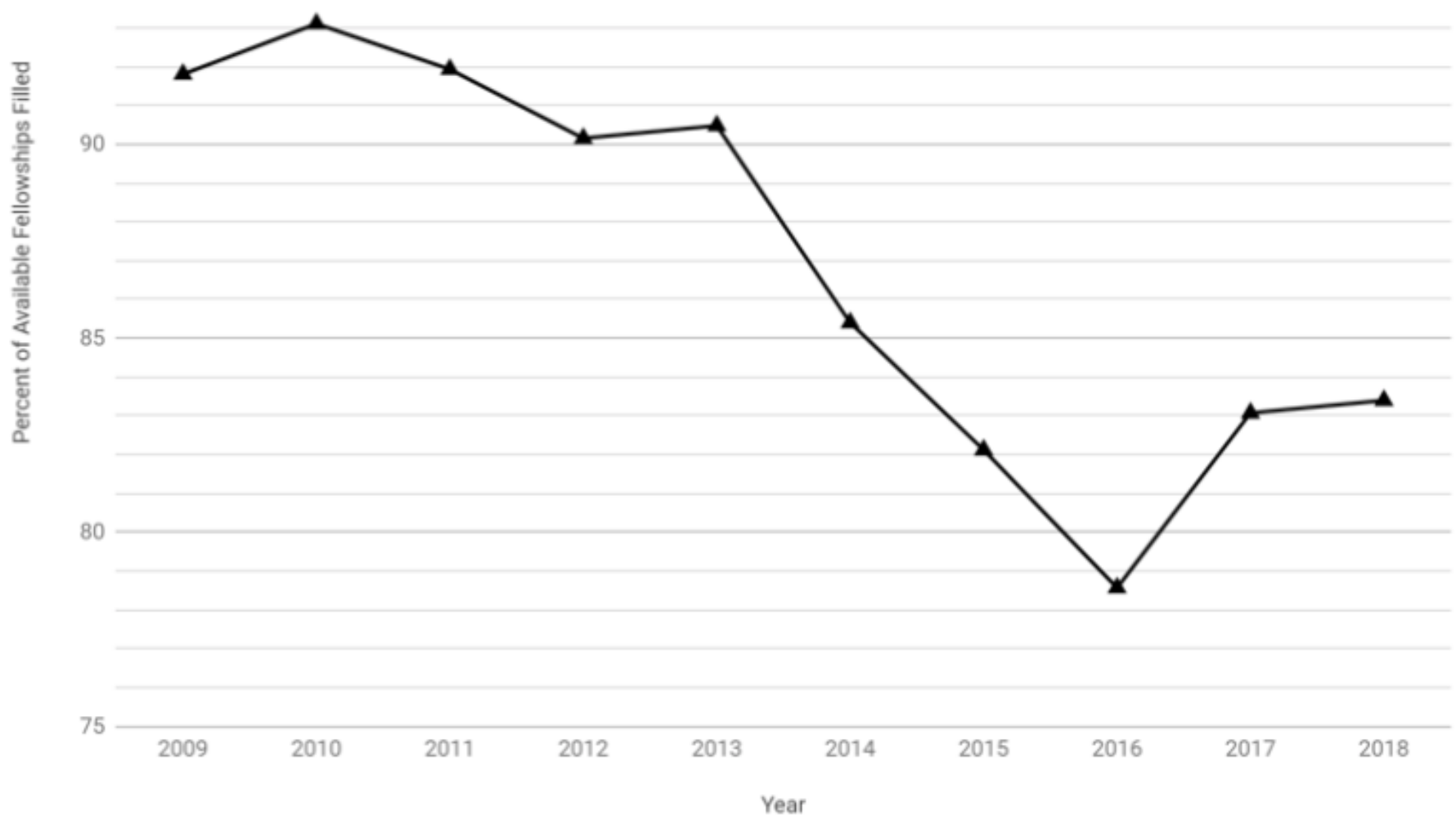

Figure 1

Percent of Available Fellowship Positions Filled Per Year, Procedural vs Non-Procedural Specialties $\boldsymbol{\Delta}$ Procedural $\otimes$ Non-Procedural 


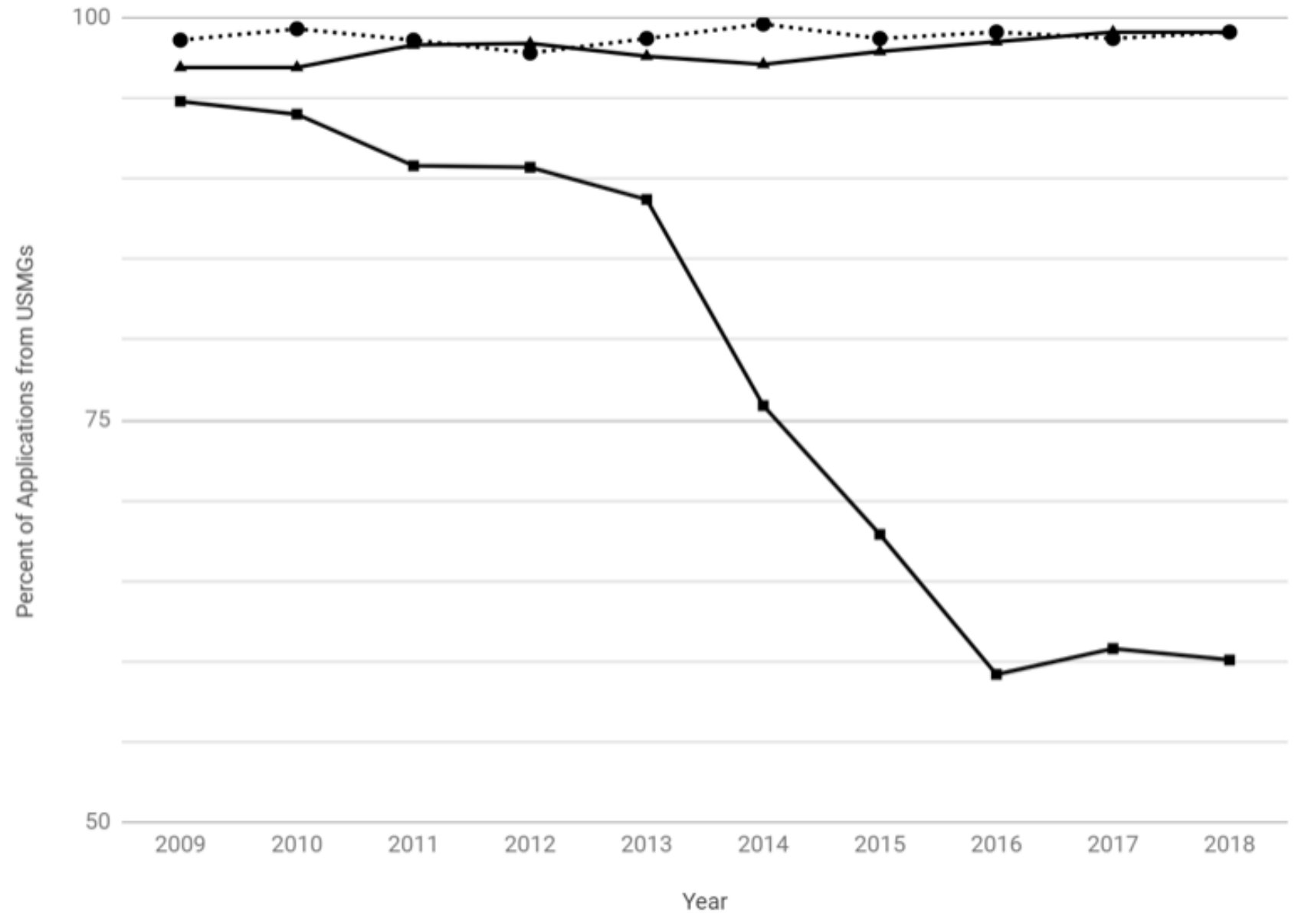

Figure 2

Percent of Available Fellowship Positions Filled Per Year, Per Specialty $\mathbf{\Delta}$ Hematology/Oncology $\mathbb{}$ Cardiology $₫$ Nephrology 


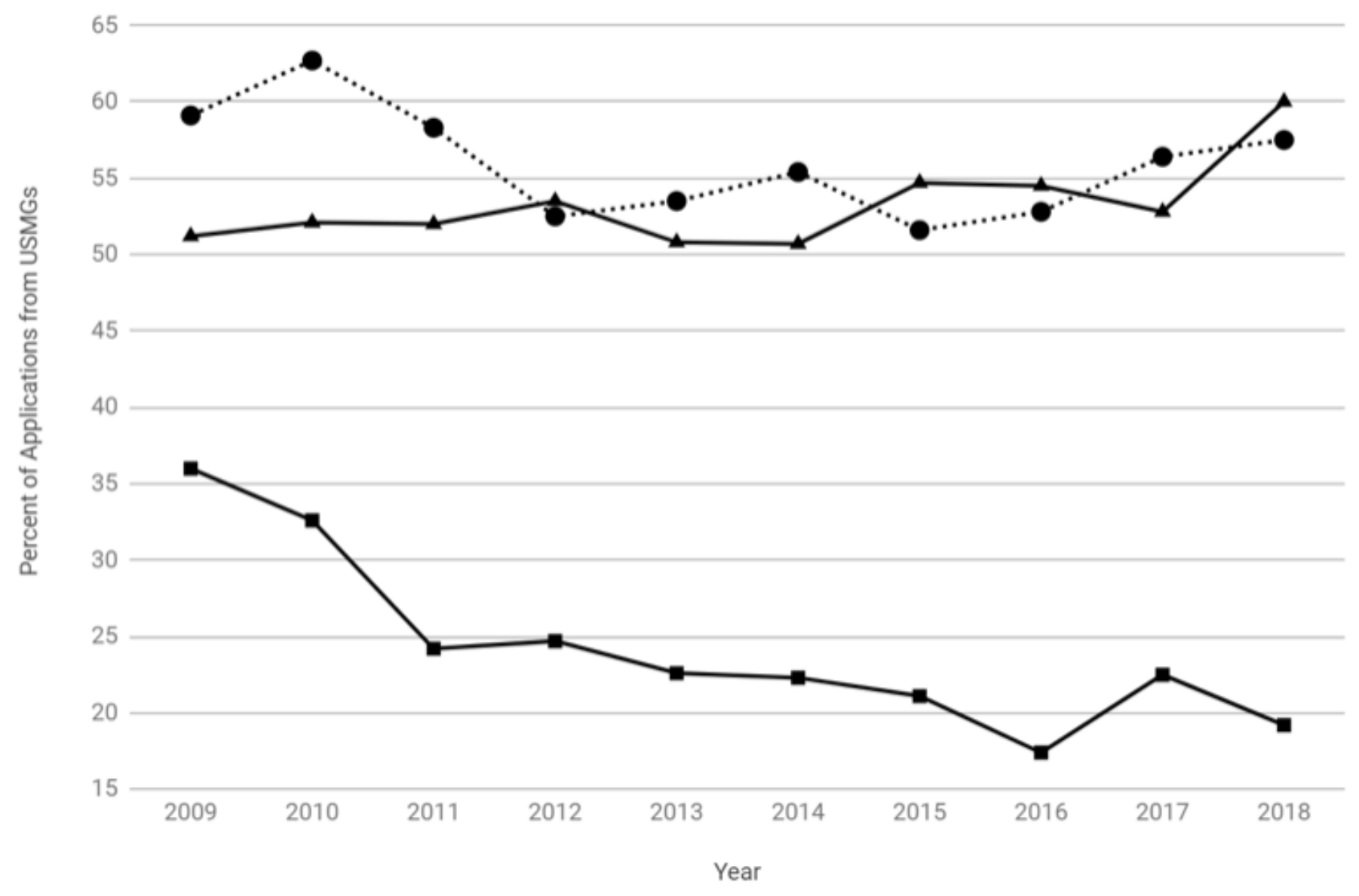

Figure 3

Percent of Fellowship Positions Filled by US Medical Graduates Per Specialty $\mathbf{\Delta}$ Hematology/Oncology $\mathbb{\nabla}$ Cardiology $\otimes$ Nephrology 